\title{
Ensinando encenando devising
}

Alexander Kelly

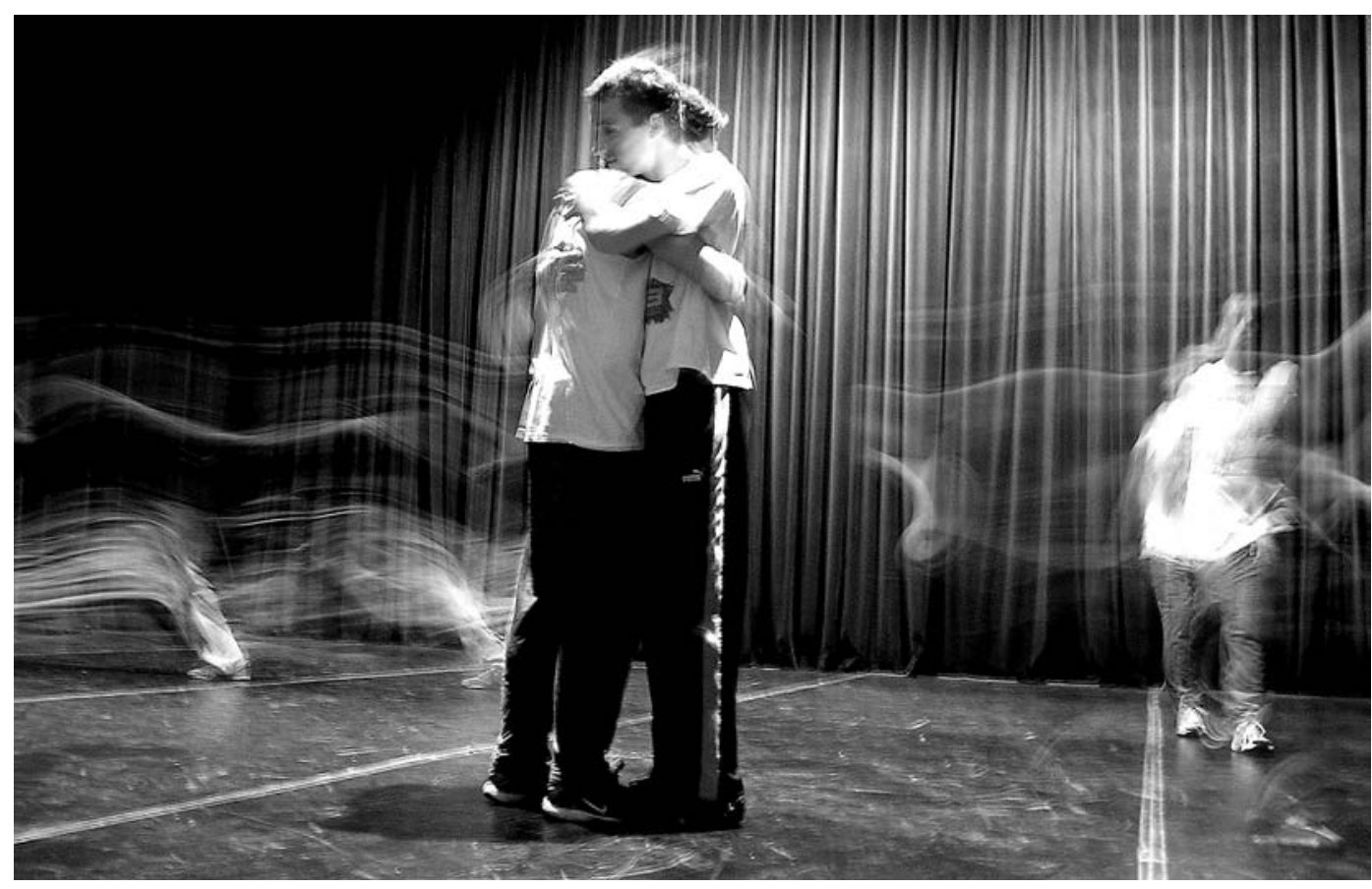

Fazer / ensinar

Os Third Angel fazem devised theatre'. Fundada em Sheffield, desde 1995 que a companhia tem apresentado pelo Reino Unido e pela Europa os seus projectos performativos e artísticos, que incluem e por vezes articulam teatro, instalação, cinema, vídeo, documentário, fotografia e design (www.thirdangel.co.uk). A prática artistica dos Third Angel é complementada com um programa de trabalho pedagógico - ensinar os processos de devising, de performance e de encenação através da feitura de um trabalho (seja ele um espectáculo em sentido estrito ou um exercicio de workshop de cinco minutos).

\section{Vias alternativas para o novo teatro}

Entre Julho e Setembro de 2004, os dois directores artísticos dos Third Angel, eu e a Rachael Walton, dirigimos durante nove semanas um curso de encenação e de devising para jovens profissionais no Centro de Arte Moderna da Fundação Calouste Gulbenkian, em Lisboa. 0 nosso trabalho prévio em Portugal ${ }^{2}$ já nos tinha ensinado que não existe nenhum equivalente português ao termo inglês devising no vocabulário teatral.

\section{0 que é o devising?}

Em caso de dúvida, é ir procurar: o meu dicionário define to devise como um verbo que significa planear ou inventar.
E apresenta os seguintes sinónimos: conceber, criar, desenhar, desenvolver, engendrar, esboçar, esquematizar, formular, idear, imaginar, inventar, magicar, planear, projectar.

É um bom começo: em devising, pode-se esperar fazer todas estas coisas.

Cada devised project é feito de maneira diferente, e essa é uma das caracteristicas do devising: trata-se de uma forma reactiva de trabalhar, que acolhe os contributos de toda a equipa criativa. E também acolhe a sorte: 0 acidente, o acaso, o inesperado ou o imprevisivel. Quando se faz devising em grupo, o objectivo é criar algo que não teria podido surgir do trabalho individual de cada um. Quando se faz devising a solo, o objectivo é desenvolver uma peça única e original, ao invés de se formular uma interpretação do guião de outra pessoa.

No teatro tradicional, o texto dramático é o ponto de partida, e o processo de ensaios consiste em passar para o palco uma interpretação desse texto. No devised theatre, qualquer outro elemento pode ser o ponto de partida: um tema, uma imagem do palco, uma ideia sobre como envolver o público, uma tarefa que se propõe aos performers. 0 trabalho de devising possibilita - na verdade, exige - dos performers uma contribuição criativa para o projecto como um todo, permitindo-Ihes um investimento maior no trabalho.
Pedro Gil, Wojtek Ziemilski, Jorge Andrade e outros, fot. Alexander Kelly.

10 verbo to devise, aqui aplicado num sentido muito especifico de concepção e invenção de um projecto performativo, não tem ainda um equivalente fácil em português. Tal como refere 0 autor mais adiante, trata-se de um termo com uma grande diversidade de significados possiveis, nenhum dos quais inteiramente feliz, pelo que se decidiu deixar ao leitor deste texto o original inglês (N.T.).

\section{${ }^{2}$ Os Third Angel} apresentaram em Portugal Where from Here (Culturgest, Novembro de 2002) e, no âmbito da Semana Internacional de Teatro (Coimbra 2003), 0 espectáculo Leave No Trace (Oficina Municipal de Teatro), a instalação Pills for Modern Living (no foyer do TAGV) e o projecto Onde éque eles esconderam as respostas? (co-produção Ao Cabo Teatro, na Rua Ferreira Borges). Leave No Trace pôde ainda ser visto no Rivoli Teatro Municipal. 


\section{Pode ensinar-se a encenar?}

Há um cliché que diz que não se pode ensinar alquém a encenar, mas que se pode ajudar alguém a encontrar a(s) forma(s) em que lhe é mais confortável trabalhar. Entre os propósitos deste curso estavam: desenvolver um conjunto de ferramentas, ou estratégias, que facultariam aos estudantes a criação de trabalho em grupos; ajudá-los a explorar diferentes modelos de direcção desse processo criativo. Os princípios que guiariam o curso eram, como tal, a investigação prática, a observação e a discussão em grupo.

\section{Observar de fora}

Só raramente os doze elementos do grupo trabalharam a parte prática juntos, ao mesmo tempo. Normalmente, seis ou oito punham-se de fora e sentavam-se a observar os colegas, avaliando o que viam, tirando notas daquilo que era útil, ou era interessante, ou tinha potencial para ser desenvolvido. Em reunião, falávamos sobre a utilidade ou interesse dessas coisas, bem como sobre as condições em que o trabalho foi criado, desenvolvido ou dirigido. Depois, discutimos sobre como essas ideias ou momentos poderiam ser potenciados para se tornarem materiais que pudessem ser incluidos numa performance.

\section{Primeira semana: Experimentar com o quotidiano} Julho de 2004. Encontrei-me com os doze estudantes à volta de uma grande mesa verde na Sala Polivalente da Fundação Gulbenkian. Importa explicar que, embora me refira a eles como "estudantes", os doze participantes do curso eram todos actores, encenadores e artistas experimentados ${ }^{3}$. Começámos com alguns exercícios baseados na experiência de vida de cada um e fazendo incursões ao mundo real.

\section{Segunda semana: Regras ou opções?}

${ }^{3}$ Os doze formandos foram: Anabela Teixeira,
0 trabalho prático do curso teve início com jogos e exercicios baseados em regras simples, nos quais os performersdevisors são confrontados com restrições, ou uma série de opções, relativamente àquilo que estão "autorizados" a fazer durante uma improvisação. As regras estão lá para nos ajudar a encontrar e a comunicar ideias e significados dentro de um vocabulário restrito. E também para nos ajudar a encontrar os momentos em que precisamos de "quebrar as regras", isto é, fazer algo que não seja "autorizado", mas que faça sentido em representação.

Estes exercícios baseados em regras são úteis porque possibilitam uma dinâmica de grupo, permitindo perceber a maneira como cada um trabalha. Também são úteis para levar os performers a fazer cada vez menos em palco: estar menos ocupados, mas continuar igualmente concentrados, igualmente presentes.

\section{Terceira semana: Autobiografia}

No processo de devising é frequente recorrermos a material autobiográfico. Isso não significa que uma peça tenha de
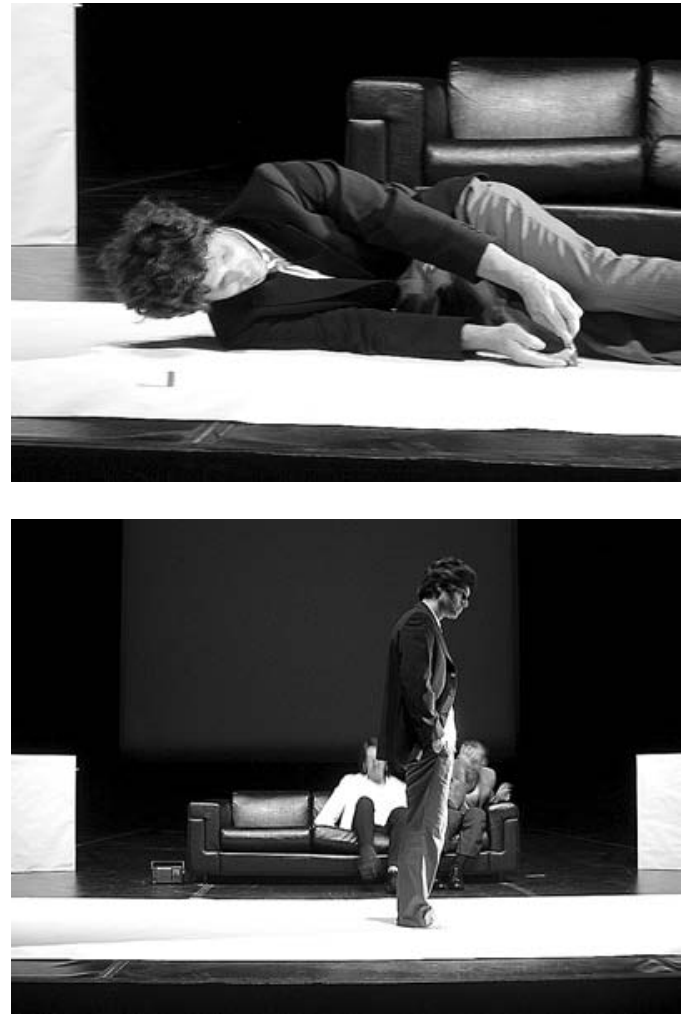

ser confessional, ou que um devisor tenha de estar preparado para expor os seus segredos mais obscuros. Pode-se mentir. Pode-se corrigir a nossa própria experiência. Mas há que estar preparado: a partir do momento em que esse material esteja na sala de ensaios, pode ser agarrado por qualquer pessoa e reutilizado, ou correspondido, ou manipulado, ou esquecido.

0 objectivo é criar um ambiente no qual os devisors estejam preparados para sugerir, verbalmente ou na prática, qualquer ideia que tenham, sem se preocuparem se a ideia é "boa" ou não. Se formos bem sucedidos na criação deste ambiente de trabalho, é inevitável que no trabalho de devising de um projecto encontremos algum material que é mau, ou desinteressante, ou que simplesmente não encaixa - ou com o outro material já existente ou com o formato que começámos a desenvolver. É importante aceitar isto e estar preparado para experimentar coisas novas, porque nunca se sabe que outras ideias poderão ter surgido aos nossos colaboradores a partir da nossa ideia inicial.

\section{Quarta semana: Texto}

0 devising não impede que se trabalhe a partir de um guião ou de um texto. De facto, a maior parte do nosso trabalho inclui muito texto dito - desde histórias improvisadas a cenas de diálogo inteiramente escritas. Tratamos o texto como mais um dos ingredientes do processo, e exploramo-lo, interrogamo-lo, brincamos com ele, antes de começar a ensaiá-lo.

Os estudantes trouxeram textos para o trabalho com o grupo: diálogos escritos por eles próprios, ou tirados de peças, de filmes ou da televisão. Também escolheram um texto não dramático, um excerto de um conto, um artigo de uma revista, um anúncio, uma carta. Tentaram interpretá-los de maneiras inadequadas, localizá-los em sítios inusitados; conduzindo os seus performers no sentido 


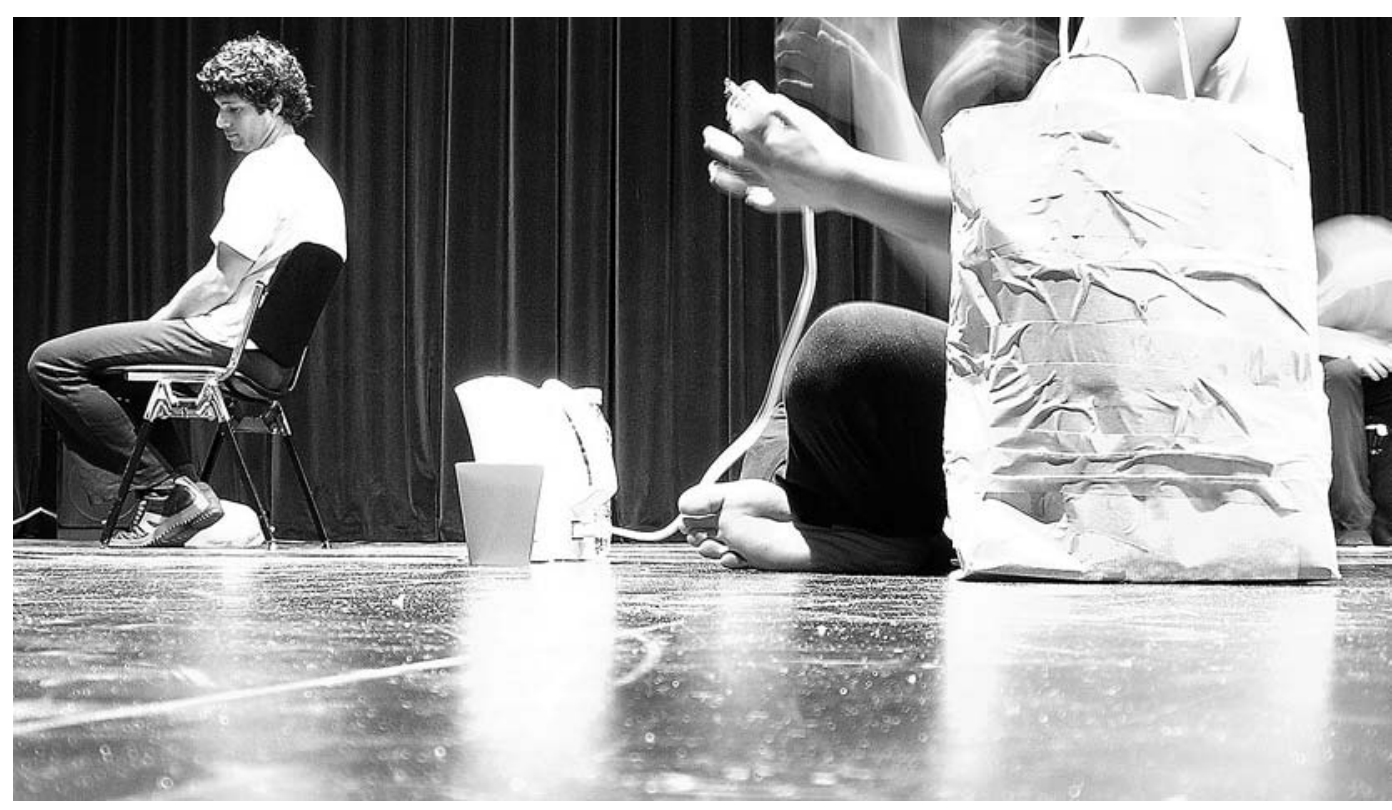

de ignorarem o contexto original das palavras e tentarem descobrir sentidos e possibilidades inesperadas.

\section{Quinta semana: Intervenção}

Os estudantes sairam para o mundo real, fora do nosso espaço de trabalho, para apresentar performances não anunciadas. Pequenas intervenções performativas nas ruas, cheias de lisboetas a fazer compras ou a correr para o trabalho e de turistas a passear e a ver as vistas. Uma performance de longa duração no anfiteatro ao ar livre do jardim da Fundação Gulbenkian, dispersa no meio de pessoas a almoçar, a ler, a dormir a sesta; um grupo de adolescentes góticos a passar.

Este trabalho foi o que suscitou maior debate, de todos os exercícios que fizemos. Estas performances são, pela sua natureza, praticamente não-ensaiáveis - podem preparar-se, mas não se podem ensaiar. Os performers descobrem coisas sobre aquilo que estão a fazer - o que funciona, o que não funciona - enquanto o estão a fazer, entre o público. Um público que não sabe que o é até ao momento em que encontra o trabalho (às vezes nem ai). Um público cuja reacção pode ser qualquer coisa. Aquele grupo de adolescentes fascinados - aperceberam-se do que se estava a passar, tentaram descobrir as regras, desafiaram-se mutuamente a entrar no jogo - e no fim cheios de perguntas. 0 que é isso quis dizer?

Sexta e sétima semanas: Encenando projectos a solo Ao trabalhar em devising, é preciso haver um encenador?

Ao trabalhar em devising, o encenador é um condutor? Um olhar de fora? Um autor?

Qual é a diferença entre ter contributos dos performers e trabalhar em devising com os performers?

Qual é a diferença entre liberdade em improvisação e liberdade em devising?

Qual é a diferença entre experimentar e devising?

Qual é a diferença entre actores e performers?

As pausas e as entoações (por exemplo) são ditadas pelo texto ou pelo encenador?

Quão preciso deve / pode o encenador ser no que diz respeito à forma como um dado texto é dito?

Ao trabalhar em devising com um grupo de performers, o que é que se faz primeiro:

a) discutir os temas que se deseja explorar?

b) lançar um exercício que será gerador de material?

c) encontrar ou construir um novo ambiente de trabalho para os performers habitarem e explorarem?

\section{Oitava semana: Dentro / fora}

Doze participantes é um bom número para um curso como este: permite-nos fazer trabalhos a solo, em pares, em grupos de três ou quatro ou seis. Na oitava semana começámos a trabalhar com todos juntos no palco, na preparação para o projecto final da nona semana. Doze performers enchem bem o palco; explorámos a ideia de alguns deles estarem simplesmente "em palco", mas estarem "sem funções", sem procurar nem exigir a atenção do público, para assim podermos focar-nos em grupos mais pequenos dentro dos doze.

\section{Nona semana: 0 espectáculo final / apresentação} Tão triste como a felicidade recordada: texto do programa

"Numa Sexta-feira à tarde, em Setembro, sentámo-nos em roda e começámos a conversar sobre a felicidade. 0 que nos fez feliz? 0 que seria a felicidade? Onde a encontrámos? Demos a nós próprios uma semana - ou melhor, 25 horas - para explorar o tema. É demasiado tempo para ficar alegre e, por vezes, as nossas caras doíam de tanto rir. 0 que se verá hoje à noite é o resultado".

\section{Excerto do texto}

"Bem vindo ao LaboratórioFeliz. 0 que estamos aqui a fazer é tentar produzir felicidade de longa duração para usufruto de todos. Algumas pessoas costumam falar da Busca da Felicidade - como se a felicidade fosse uma coisa que se pudesse simplesmente capturar e levar para casa. Mas isso também quer dizer que essa busca poderá nunca acabar, que a felicidade poderá nunca ser apanhada. Bem- vindo ao LaboratórioFeliz".

Tradução de Mónica Guerreiro

Agradecimento a Jorge Andrade
Despeja o conteúdo da tua mala ou pasta para cima da mesa, à frente do grupo. Fala-nos de um dos objectos que transportas contigo. Evidentemente, não tens de dizer a verdade.

Apresenta a tua vida em um minuto. Assiste à apresentação da vida dos outros em um minuto. Repete a tua. Em que é que ela se alterou?

\section{Sai e observa a tua} cidade. Tenta interromper 0 quotidiano com pequenas "experiências". Repara num estranho à janela. Veste roupas que não têm nada a ver contigo. Desce vinte lances de escadas ou mais. Conta até mil o mais alto que puderes.

Documenta as tuas experiências. Faz uma performance inspirada nessas experiências.

No trabalho em grupo, podem sentarse, ficar de pé ou andar. Podem interagir uns com os outros, mas não se podem tocar. Têm 30 minutos.

Entra em contacto com um amigo. Pede-lhe que te escreva uma carta sobre o seu dia. DizIhe que a carta será lida em público. DizIhe que só irás ler a carta no momento em que a estiveres a ler em público. 